\title{
Penerapan Algoritma Apriori Dalam Memprediksi Hasil Penjualan Sparepart PC (Studi Kasus : Toko Sentra Computer)
}

\author{
Silvi Sintia, Poningsih, Ilham Syahputra Saragih, Anjar Wanto, Irfan Sudahri Damanik \\ Sekolah Tinggi Ilmu Komputer (STIKOM) Tunas Bangsa, Indonesia \\ Jalan Jend Sudirman Blok A No. 1-3 Pematangsiantar 21127, Indonesia, Telp. (0622) 22431 \\ Email : Silvisintia07@gmail.com
}

\begin{abstract}
Technological advances are increasing and becoming an important need for everyday life both in the fields of education, economics, social, culture and politics. One of the technologies needed by society is computers. Sentra Computer is a store engaged in the sale of computers. The researcher has conducted research at the Computer Center Store and found a problem when the stock of PC spare parts that cost more than Rp. 450,000 is often insufficient because the stock is bought with a small amount so that capital can be used on a cheaper PC spare part. The purpose of this thesis research is to find out the sales data of PC spare parts at the Sentra Computer Shop which are most purchased by consumers. The methodology used is a priori algorithm by calculating the value of support and the value of confidence carried out manually and computerized using rapidminer. The result is that the Sentra Computer Store owner can provide sufficient stock.
\end{abstract}

Keywords: Sparepart PC, Algoritma Apriori, Support, Confidence, Rapidminer.

Abstrak- Kemajuan teknologi semakin meningkat dan menjadi suatu kebutuhan yang penting bagi kehidupan sehari - hari baik dalam bidang pendidikan, ekonomi, sosial, budaya, dan politik. Salah satu teknologi yang dibutuhkan oleh masyarakat adalah komputer. Sentra Computer adalah toko yang bergerak dibidang penjualan komputer. Peniliti telah melakukan penelitian pada Toko Sentra Computer dan menemukan masalah ketika stok Sparepart PC yang harganya diatas Rp. 450.000 sering tidak tercukupi karena stok yang dibeli dengan jumlah yang sedikit agar modal bisa dimanfaatkan ke Sparepart PC yang lebih murah. Tujuan penelitian skripsi ini adalah untuk mengetahui data penjualan Sparepart PC pada Toko Sentra Computer yang paling banyak dibeli oleh konsumen. Metodologi yang digunakan adalah algoritma apriori dengan menghitung nilai support dan nilai confidence yang dilakukan secara manual dan komputerisasi menggunakan rapidminer. Hasilnya adalah pemilik Toko Sentra Computer dapat mencukupi ketersediaan stok barang.

Kata Kunci: Sparepart PC, Algoritma Apriori, Support, Confidence, Rapidminer.

\section{PENDAHULUAN}

Kemajuan teknologi semakin meningkat dan menjadi kebutuhan dalam kehidupan sehari-hari baik dibidang pendidikan, sosial, budaya, politik dan ekonomi. Toko Sentra Computer bergerak dibidang ekonomi melalui penjualan Sparepart $P C$. Pada saat ini Sentra Computer sering mengalami kehabisan stok Sparepart Pc dan masih melakukan transaksi dengan mencatat data transaksi kedalam buku kemudian melakukan input data kedalam komputer yang hanya berfungsi sebagai arsip toko. Data transaksi tersebut dapat digunakan 
memprediksi hasil kombinasi penjualan Sparepart PC dengan menggunakan algoritma apriori dalam data mining. Data mining merupakan proses ekstrasi data menjadi informasi yang sebelumnya belum tersampaikan, dengan teknik yang tepat proses data mining akan memberikan hasil yang optimal [1]. Algoritma Apriori adalah algoritma pengambilan data dengan aturan asosiatif (association rule) untuk menentukan hubungan asosiatif suatu kombinasi item [2].

Dengan menggunakan algoritma apriori diharapkan membantu pimpinan mengetahui data penjualan Sparepart PC yang paling banyak dibeli oleh konsumen sehingga dapat diperbanyak pengadaannya dan mengetahui Sparepart PC lainnya yang kemungkinan akan terjual ketika konsumen membeli salah satu dari Sparepart PC yang bernilai Rp.450.000,- s/d Rp.1.500.000,-.

\section{METODOLOGI PENELITIAN}

Data Mining telah menarik banyak perhatian dalam dunia sistem informasi dan dalam masyarakat secara keseluruhan dalam beberapa tahun terakhir, karena ketersediaan luas dalam jumlah besar data dan kebutuhan segera untuk mengubah data tersebut menjadi informasi yang berguna dan pengetahuan [3]-[6]. Data Mining merupakan suatu proses penggalian data atau penyaringan data dengan memanfaatkan kumpulan data dengan ukuran yang cukup besar melalui serangkaian proses untuk mendapatkan informasi yang berharga dari data tersebut [7]. Data Mining untuk mengekstraksikan atau menambang pengetahuan dari kumpulan banyak data [2].

\subsection{Algoritma Apriori}

Algoritma Apriori adalah salah satu algoritma pada bidang data mining untuk penggalian aturan asosiasi atau yang lebih dikenal dengan istilah association rule mining [8]. Tahap ini mencari kombinasi item yang memenuhi syarat minimum dari nilai support dalam basis data. Nilai support sebuah item diperoleh dengan menggunakan rumus berikut [9].

Support $A=\frac{\text { Jumlah Transaksi Mengandung } A}{\text { Total Transaksi }} * 100 \%$

Sementara, nilai support dari 2 item diperoleh dengan menggunakan rumus [7]:

Support $(A, B)=P(A \cap B)$

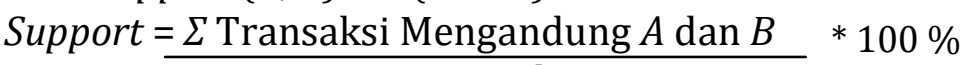
$\sum$ Transaksi

Setelah semua frekuensi tinggi ditemukan, barulah dicari aturan asosiasi yang memenuhi syarat minimum untuk confidence dengan menghitung confidence aturan asosiatif. Diperoleh dengan rumus berikut [10]:

Confidence $=\underline{\Sigma \text { Transaksi Mengandung } A \text { dan } B} * 100 \%$

$$
\Sigma \text { Transaksi } A
$$

Sedangkan bila mencari rumus nilai support dari 2 item [6]: 


$$
=\frac{\sum \text { Transaksi Mengandung } A \text { dan } B}{\sum \text { Transaksi } A} * 100 \%
$$

Support (nilai penunjang) adalah persentase kombinasi item tersebut dalam database, sedangkan confidence (nilai kepastian) adalah kuatnya hubungan antar item dalam aturan asosiasi [2].

\subsection{Rapidminer}

Rapidminer merupakan perangkat lunak yang dibuat oleh Dr. Markus Hofmann dari Institude Of Technologi Blanchardstown dan Ralf Klinkenberg dari rapid-i.com dengan tampilan GUI (Graphical User Interface) sehingga memudahkan pengguna dalam menggunakan perangkat lunak ini [11].

\section{HASIL DAN PEMBAHASAN}

Peneliti mendapatkan data dari dokumentasi yang berupa buku penjualan dan file serta melakukan pengamatan langsung melihat kebutuhan dan ketersediaan stok Sparepart $P C$. Data yang digunakan untuk penelitian menggunakan metode sampling yaitu mengambil sebagian data yang dapat dilihat sebagai berikut :

Tabel 1. Harga Sparepart PC Rp. 450.000 s/d Rp.1.500.000

\begin{tabular}{|l|l|l|}
\hline No. & Sparepart PC & Harga \\
\hline 1 & Ram & Rp. 450.000,- \\
\hline 2 & Hardisk & Rp. 550.000,- \\
\hline 3 & Lcd & Rp. 1.050.000,- \\
\hline 4 & Motherboard & Rp. 700.000,- \\
\hline 5 & Processor & Rp. 1.500.000,- \\
\hline
\end{tabular}

Tabel 2. Transaksi 01 Desember s/d 31 Desember 2018

\begin{tabular}{|l|l|l|}
\hline No. & Sparepart PC & Keterangan \\
\hline 1. & Flashdisk, cd-rw, card reader, sound card, keyboard. & Nihil \\
\hline 2. & $\begin{array}{l}\text { Mouse, mousepad, headshet, power supply, } \\
\text { headshet. }\end{array}$ & Nihil \\
\hline 3. & $\begin{array}{l}\text { Processor, flashdisk, motherboard, card reader, } \\
\text { switch hub, lcd. }\end{array}$ & $\begin{array}{l}\text { Terdapat } 3 \text { buah dari tabel } \\
\text { harga Sparepart PC }\end{array}$ \\
\hline 4. & $\begin{array}{l}\text { Hardisk case, power supply, keyboard, mouse, } \\
\text { notebook coolingpad. }\end{array}$ & Nihil \\
\hline 5. & $\begin{array}{l}\text { Cd-room, hardisk case, motherboard, hardisk, } \\
\text { ram, case power supply. }\end{array}$ & $\begin{array}{l}\text { Terdapat } 3 \text { buah dari tabel } \\
\text { harga Sparepart PC }\end{array}$ \\
\hline 6. & $\begin{array}{l}\text { Baterai c-mosh, adaptor universal, fan processor, } \\
\text { kabel printer. }\end{array}$ & Nihil \\
\hline 7. & $\begin{array}{l}\text { Range extender, mousepad, usb hub, kabel power } \\
\text { laptop, switch hub. }\end{array}$ & Nihil \\
\hline 8. & $\begin{array}{l}\text { Ram, dvd-rw, motherboard, lcd, flashdisk, } \\
\text { catridge. }\end{array}$ & $\begin{array}{l}\text { Terdapat } 3 \text { buah dari tabel } \\
\text { harga Sparepart PC }\end{array}$ \\
\hline 9. & $\begin{array}{l}\text { Switch hub, dvd-room, cashing cpu, ssd, catridge, } \\
\text { keyboard. }\end{array}$ & Nihil \\
\hline 10. & $\begin{array}{l}\text { Adaptor, usb sound, kabel hdmi, konverter hdmi to } \\
\text { vga. }\end{array}$ & Nihil \\
\hline 11. & Motherboard, kabel power cpu, hardisk, ram, & Terdapat 3 buah dari tabel \\
\hline
\end{tabular}

Penerapan Algoritma Apriori Dalam Memprediksi Hasil Penjualan Sparepart PC (Silvi Sintia)|912 


\begin{tabular}{|c|c|c|}
\hline No. & Sparepart PC & Keterangan \\
\hline & power supply, mouse, lan card, usb sound. & harga Sparepart PC \\
\hline 12. & $\begin{array}{l}\text { Fan cashing, flashdisk, otg, kabel vga, speaker, } \\
\text { notebook coolingpad. }\end{array}$ & Nihil \\
\hline 13. & $\begin{array}{l}\text { Ram, keyboard, baterai laptop, hardisk, } \\
\text { processor, power supply. }\end{array}$ & $\begin{array}{l}\text { Terdapat } 3 \text { buah dari tabel } \\
\text { harga Sparepart PC }\end{array}$ \\
\hline 14. & $\begin{array}{l}\text { Speaker, catridge, fan cashing, baterai c-mosh, } \\
\text { kabel power laptop. }\end{array}$ & Nihil \\
\hline 15. & $\begin{array}{l}\text { Kabel audio, mousepad, lcd, processor, dvd-room, } \\
\text { hardisk. }\end{array}$ & $\begin{array}{l}\text { Terdapat } 3 \text { buah dari tabel } \\
\text { harga Sparepart } P C\end{array}$ \\
\hline 16. & $\begin{array}{l}\text { Power supply, mouse, konverter hdmi to vga, kabel } \\
\text { printer. }\end{array}$ & Nihil \\
\hline 17. & $\begin{array}{l}\text { Flashdisk, kabel vga, cashing cpu, speaker, power } \\
\text { supply. }\end{array}$ & Nihil \\
\hline 18. & $\begin{array}{l}\text { Baterai laptop, hardisk case, headsher, otg, } \\
\text { keyboard, notebook coolingpad. }\end{array}$ & Nihil \\
\hline 19. & $\begin{array}{l}\text { Ram, keyboard, Icd, motherboard, otg, konverter } \\
\text { hdmi to vga. }\end{array}$ & $\begin{array}{l}\text { Terdapat } 3 \text { buah dari tabel } \\
\text { harga Sparepart PC }\end{array}$ \\
\hline 20. & $\begin{array}{l}\text { Card reader, usb lan, catridge, notebook } \\
\text { coolingpad. }\end{array}$ & Nihil \\
\hline 21. & $\begin{array}{l}\text { Keyboard, kabel vga, otg, kabel audio, switch hub, } \\
\text { usb hub. }\end{array}$ & Nihil \\
\hline 22. & $\begin{array}{l}\text { Mousepad, motherboard, power supply, kabel } \\
\text { power cpu, ram, lcd. }\end{array}$ & $\begin{array}{l}\text { Terdapat } 3 \text { buah dari tabel } \\
\text { harga Sparepart PC }\end{array}$ \\
\hline 23. & $\begin{array}{l}\text { Switch hub, keyboard, kabel audio, usb sound, lan } \\
\text { card. }\end{array}$ & Nihil \\
\hline 24. & $\begin{array}{l}\text { Adaptor, cashing cpu, power supply, fan processor, } \\
\text { pasta. }\end{array}$ & Nihil \\
\hline 25. & $\begin{array}{l}\text { Hardisk case, speaker, kabel audio, konverter hdmi } \\
\text { to vga. }\end{array}$ & Nihil \\
\hline 26. & $\begin{array}{l}\text { Fan cashing, flashdisk, range extender, cd-rw, card } \\
\text { reader. }\end{array}$ & Nihil \\
\hline 27. & $\begin{array}{l}\text { Hardisk, keyboard, mouse, ram, motherboard, } \\
\text { baterai laptop. }\end{array}$ & $\begin{array}{l}\text { Terdapat } 3 \text { buah dari tabel } \\
\text { harga Sparepart PC }\end{array}$ \\
\hline 28. & $\begin{array}{l}\text { Hardisk case, kabel hdmi, keyboard, lan card, kabel } \\
\text { audio. }\end{array}$ & Nihil \\
\hline 29. & $\begin{array}{l}\text { Catridge, fan processor, flashdisk, audio sound, } \\
\text { mousepad. }\end{array}$ & Nihil \\
\hline 30. & Card reader, hardisk case, cashing cpu, fan cashing. & Nihil \\
\hline 31. & $\begin{array}{l}\text { Kabel vga, Icd, kabel audio, ram, hardisk, } \\
\text { notebook coolingpad. }\end{array}$ & $\begin{array}{l}\text { Terdapat } 3 \text { buah dari tabel } \\
\text { harga Sparepart PC }\end{array}$ \\
\hline
\end{tabular}

Tabel 3. Data Transaksi Rp. 450.000 s/d Rp. 1.500 .000

\begin{tabular}{|l|l|l|}
\hline NO. & Tanggal & Item \\
\hline 1. & $03-12-2018$ & Processor, lcd, motherboard \\
\hline 2. & $05-12-2018$ & Motherboard, hardisk, ram \\
\hline 3. & $08-12-2018$ & Ram, motherboard, lcd \\
\hline 4. & $11-12-2018$ & Motherboard, hardisk, ram \\
\hline 5. & $13-12-2018$ & Ram, hardisk, processor \\
\hline 6. & $15-12-2018$ & Lcd, processor, hardisk \\
\hline 7. & $19-12-2018$ & Ram, motherboard, lcd \\
\hline 8. & $22-12-2018$ & Motherboard, ram, lcd \\
\hline 9. & $27-12-2018$ & Hardisk, ram, motherboard \\
\hline
\end{tabular}




\begin{tabular}{|l|l|l|}
\hline NO. & Tanggal & Item \\
\hline 10. & $31-12-2018$ & Lcd, ram, hardisk \\
\hline
\end{tabular}

Tabel diatas adalah data yang akan dihitung nilai support C1 yang akan diberikan nilai minimum support $60 \%$ pada $C 1$ dan data yang tidak memenuhi nilai minimum Support C1 tidak akan dimasukkan ke $C 2$ sampai dengan $C n$. Berikut adalah perhitungan nilai Support C1.

Support C1 = Jumlah Transaksi / Total Transaksi * $100 \%$.

Tabel 4. Support C1

\begin{tabular}{|l|l|l|l|}
\hline No. & Sparepart PC & Jumlah Transaksi & Nilai Support \% \\
\hline 1 & Ram & 8 & $8 / 10 * 100 \%=80 \%$ \\
\hline 2 & Hardisk & 6 & $6 / 10 * 100 \%=60 \%$ \\
\hline 3 & Lcd & 6 & $6 / 10 * 100 \%=60 \%$ \\
\hline 4 & Motherboard & 7 & $7 / 10 * 100 \%=70 \%$ \\
\hline 5 & Processor & 3 & $3 / 10 * 100 \%=30 \%$ \\
\hline Minimum Support & $\mathbf{6 0 \%}$ \\
\hline
\end{tabular}

Nilai support C1 processor tidak memenuhi nilai minimum support C1 maka tidak dimasukkan ke $C 2$ sampai dengan $C n$. Berikut adalah perhitungan nilai support $\mathrm{C} 3 / \mathrm{Cn}$.

Support C3/Cn = Jumlah Transaksi $/$ Total Transaksi * $100 \%$.

Tabel 5. Support C3/Cn

\begin{tabular}{|l|l|l|l|}
\hline No. & Sparepart PC & Jumlah Transaksi & Nilai Support \% \\
\hline 1 & Ram, Hardisk, Lcd & 1 & $1 / 10 * 100 \%=10 \%$ \\
\hline 2 & Ram, Hardisk, Motherboard & 3 & $3 / 10 * 100 \%=30 \%$ \\
\hline 3 & Ram, Lcd, Motherboard & 3 & $3 / 10 * 100 \%=30 \%$ \\
\hline 4 & Hardisk, Lcd, Motherboard & - & - \\
\hline
\end{tabular}

Setelah nilai support $\mathrm{Cn}$ didapat maka dilakukan perhitungan nilai confidence C2 sampai dengan $C n$ dan diberikan nilai minimum confidence $70 \%$. Berikut adalah perhitungan nilai confidence $C 2$.

Confidence C2 =Jumlah Transaksi Mengandung A dan B/Jumlah Transaksi A*100 \%

Tabel 6. Confidence $C 2$

\begin{tabular}{|l|l|l|l|}
\hline No. & Sparepart PC & $\begin{array}{l}\text { Jumlah } \\
\text { Transaksi }\end{array}$ & Nilai Confidence \% \\
\hline 1 & Jika membeli Ram maka akan membeli Hardisk & 5 & $5 / 8 * 100 \%=62 \%$ \\
\hline 2 & Jika membeli Ram maka akan membeli Lcd & 4 & $4 / 8 * 100 \%=50 \%$ \\
\hline 3 & Jika membeli Ram maka akan membeli Motherboard & 6 & $6 / 8 * 100 \%=75 \%$ \\
\hline 4 & Jika membeli Hardisk maka akan membeli Ram & 5 & $5 / 6 * 100 \%=83 \%$ \\
\hline 5 & Jika membeli Hardisk maka akan membeli Lcd & 2 & $2 / 6 * 100 \%=33 \%$ \\
\hline 6 & $\begin{array}{l}\text { Jika membeli Hardisk maka akan membeli } \\
\text { Motherboard }\end{array}$ & 3 & $3 / 6^{*} 100 \%=50 \%$ \\
\hline 7 & Jika membeli Lcd maka akan membeli Ram & 4 & $4 / 6 * 100 \%=66 \%$ \\
\hline 8 & Jika membeli Lcd maka akan membeli Hardisk & 2 & $2 / 6 * 100 \%=33 \%$ \\
\hline 9 & Jika membeli Lcd maka akan membeli Motherboard & 4 & $4 / 6 * 100 \%=66 \%$ \\
\hline 10 & Jika membeli Motherboard maka akan membeli Ram & 6 & $6 / 7 * 100 \%=85 \%$ \\
\hline
\end{tabular}




\begin{tabular}{|l|l|l|l|}
\hline No. & Sparepart PC & $\begin{array}{l}\text { Jumlah } \\
\text { Transaksi }\end{array}$ & Nilai Confidence \% \\
\hline 11 & $\begin{array}{l}\text { Jika membeli Motherboard maka akan membeli } \\
\text { Hardisk }\end{array}$ & 3 & $3 / 7 * 100 \%=42 \%$ \\
\hline 12 & Jika membeli Motherboard maka akan membeli Lcd & 4 & $4 / 7 * 100 \%=57 \%$ \\
\hline & Minimum Confidence & & $\mathbf{7 0 \%}$ \\
\hline
\end{tabular}

Setelah nilai confidence C2 didapat maka dilakukan perhitungan sampai dengan nilai confidence $\mathrm{Cn}$. Berikut adalah perhitungan nilai confidence $\mathrm{C} 3 / \mathrm{Cn}$. Confidence $\mathrm{C} 3 / \mathrm{Cn}=$ Jumlah Transaksi Mengandung A, B dan C / Jumlah Transaksi A dan B * $100 \%$

Tabel 7. Confidence $\mathrm{C} 3 / \mathrm{Cn}$

\begin{tabular}{|c|c|c|c|}
\hline No & Sparepart PC & $\begin{array}{l}\text { Jumlah } \\
\text { Transaksi }\end{array}$ & Nilai Confidence \% \\
\hline 1 & Jika membeli Ram, Hardisk, maka akan membeli Lcd & 1 & $1 / 5 * 100 \%=20 \%$ \\
\hline 2 & $\begin{array}{l}\text { Jika membeli Ram, Hardisk, maka akan membeli } \\
\text { Motherboard }\end{array}$ & 3 & $3 / 5 * 100 \%=60 \%$ \\
\hline 3 & Jika membeli Ram, Lcd, maka akan membeli Hardisk & 1 & $1 / 4 * 100 \%=25 \%$ \\
\hline 4 & $\begin{array}{l}\text { Jika membeli Ram, Lcd, maka akan membeli } \\
\text { Motherboard }\end{array}$ & 3 & $3 / 4 * 100 \%=75 \%$ \\
\hline 5 & $\begin{array}{l}\text { Jika membeli Ram, Motherboard, maka akan membeli } \\
\text { Hardisk }\end{array}$ & 3 & $3 / 6 * 100 \%=50 \%$ \\
\hline 6 & $\begin{array}{l}\text { Jika membeli Ram, Motherboard, maka akan membeli } \\
\text { Lcd }\end{array}$ & 3 & $3 / 6 * 100 \%=50 \%$ \\
\hline 7 & Jika membeli Hardisk, Ram, maka akan membeli Lcd & 1 & $1 / 5 * 100 \%=20 \%$ \\
\hline 8 & $\begin{array}{l}\text { Jika membeli Hardisk, Ram, maka akan membeli } \\
\text { Motherboard }\end{array}$ & 3 & $3 / 5 * 100 \%=60 \%$ \\
\hline 9 & Jika membeli Hardisk, Lcd, maka akan membeli Ram & 1 & $1 / 2 * 100 \%=50 \%$ \\
\hline 10 & $\begin{array}{l}\text { Jika membeli Hardisk, Lcd, maka akan membeli } \\
\text { Motherboard }\end{array}$ & - & - \\
\hline 11 & $\begin{array}{l}\text { Jika membeli Hardisk, Motherboard, maka akan } \\
\text { membeli Ram }\end{array}$ & 3 & $3 / 3 * 100 \%=100 \%$ \\
\hline 12 & $\begin{array}{l}\text { Jika membeli Hardisk, Motherboard, maka akan } \\
\text { membeli Lcd }\end{array}$ & - & - \\
\hline 13 & Jika membeli Lcd, Ram, maka akan membeli HARDISK & 1 & $1 / 4 * 100 \%=25 \%$ \\
\hline 14 & $\begin{array}{l}\text { Jika membeli Lcd, Ram, maka akan membeli } \\
\text { Motherboard }\end{array}$ & 3 & $3 / 4 * 100 \%=75 \%$ \\
\hline 15 & Jika membeli Lcd, Hardisk, maka akan membeli Ram & 1 & $1 / 2 * 100 \%=50 \%$ \\
\hline 16 & $\begin{array}{l}\text { Jika membeli Lcd, Hardisk, maka akan membeli } \\
\text { Motherboard }\end{array}$ & - & - \\
\hline 17 & $\begin{array}{l}\text { Jika membeli Lcd, Motherboard, maka akan membeli } \\
\text { Ram }\end{array}$ & 3 & $3 / 4 * 100 \%=75 \%$ \\
\hline 18 & $\begin{array}{l}\text { Jika membeli Lcd, Motherboard, maka akan membeli } \\
\text { Hardisk }\end{array}$ & - & - \\
\hline 19 & $\begin{array}{l}\text { Jika membeli Motherboard, Ram, maka akan membeli } \\
\text { Hardisk }\end{array}$ & 3 & $2 / 6 * 100 \%=33 \%$ \\
\hline 20 & $\begin{array}{l}\text { Jika membeli Motherboard, Ram, maka akan membeli } \\
\text { Lcd }\end{array}$ & 3 & $3 / 6 * 100 \%=50 \%$ \\
\hline 21 & $\begin{array}{llll}\text { Jika membeli Motherboard, Hardisk, maka akan } \\
\text { membeli Ram }\end{array}$ & 3 & $1 / 3 * 100 \%=33 \%$ \\
\hline 22 & $\begin{array}{l}\text { Jika membeli Motherboard, Hardisk, maka akan } \\
\text { membeli Lcd }\end{array}$ & - & - \\
\hline 23 & Jika membeli Motherboard, Lcd, maka akan membeli & 3 & $3 / 4 * 100 \%=75 \%$ \\
\hline
\end{tabular}

Penerapan Algoritma Apriori Dalam Memprediksi Hasil Penjualan Sparepart PC (Silvi Sintia) $\mid 915$ 


\begin{tabular}{|l|l|l|l|}
\hline $\begin{array}{l}\text { No } \\
.\end{array}$ & Sparepart PC & $\begin{array}{l}\text { Jumlah } \\
\text { Transaksi }\end{array}$ & Nilai Confidence \% \\
\hline & Ram & & \\
\hline 24 & $\begin{array}{l}\text { Jika membeli Motherboard, Lcd, maka akan membeli } \\
\text { Hardisk }\end{array}$ & - & - \\
\hline 16 & $\begin{array}{l}\text { Jika membeli Lcd, Hardisk, maka akan membeli } \\
\text { Motherboard }\end{array}$ & - & - \\
\hline
\end{tabular}

Nilai confidence $C 2$ dan C3/Cn yang tidak memenuhi nilai minimum confidence tidak akan dimasukkan tahap akhir. Berikut adalah hasil akhir perhitungan confidence.

Tabel 8. Hasil Akhir Confidence C2

\begin{tabular}{|l|l|l|}
\hline No. & Transaksi & Confidence \% \\
\hline 1 & Jika membeli Ram maka akan membeli Motherboard & $75 \%$ \\
\hline 2 & Jika membeli Hardisk maka akan membeli Ram & $83 \%$ \\
\hline 3 & Jika membeli Motherboard maka akan membeli Ram & $85 \%$ \\
\hline
\end{tabular}

Tabel 9. Hasil Akhir Confidence C3/Cn

\begin{tabular}{|l|l|l|}
\hline No. & Transaksi & Confidence \% \\
\hline 1 & Jika membeli Ram, Lcd, maka akan membeli Motherboard & $75 \%$ \\
\hline 2 & Jika membeli Hardisk, Motherboard, maka akan membeli Ram & $100 \%$ \\
\hline 3 & Jika membeli Lcd, Ram, maka akan membeli Motherboard & $75 \%$ \\
\hline 4 & Jika membeli Lcd, Motherboard, maka akan membeli Ram & $75 \%$ \\
\hline 5 & Jika membeli Motherboard, Lcd, maka akan membeli Ram & $75 \%$ \\
\hline
\end{tabular}

Hasil akhir confidence akan dibandingkan dengan hasil akhir menggunakan software rapidminer dengan nilai minimum support dan confidence yang sama. Berikut adalah hasil akhir rapidminer.

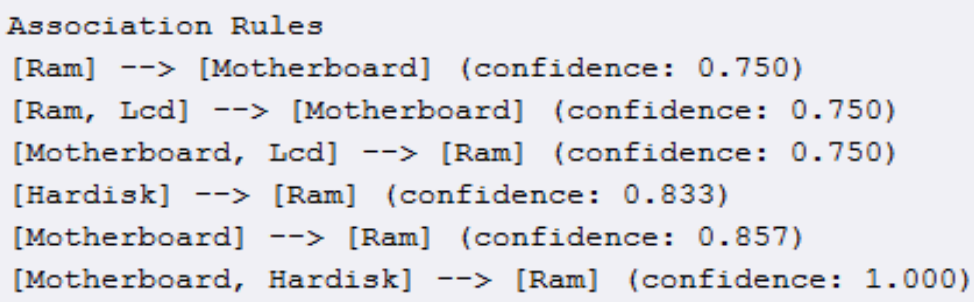

Gambar 1. Hasil Akhir Confidence Menggunakan Rapidminer

\section{KESIMPULAN}

Berdasarkan hasil perhitungan diatas didapat nilai confidence ram adalah yang paling tinggi dan perbandingan hitungan manual dengan menggunakan software rapidminer memberikan hasil yang sama. Makadari itu pimpinan Toko Sentra Computer dapat menyediakan stok Sparepart $P C$ yang paling laku agar tercukupi dengan minat konsumen dan Sparepart $P C$ yang tingkat penjualannya rendah agar lebih dipromosikan kepada konsumen. Untuk penelitian selanjutnya 
agar menambah atribut tidak hanya Sparepart $P C$, misalnya menambahkan waktu setiap transaksi.

\section{DAFTAR PUSTAKA}

[1] Abdillah, G., Putra, F. A. and Renaldi, F. (2016) 'Penerapan Data Mining Pemakaian Air Pelanggan Untuk Menentukan Klasifikasi Potensi Pemakaian Air Pelanggan Baru Di PDAM TIRTA RAHARJA Menggunakan Algoritma K-Means', Seminar Nasional Teknologi Informasi dan Komunikasi 2017 (Sentika 2016), pp. 498-506.

[2] Badrul, M. (2016) 'Algoritma Asosiasi Dengan Algoritma Apriori Untuk Analisa Data Penjualan', Jurnal Pilar Nusa Mandiri, 11(2), pp. 121-129.

[3] M. G. Sadewo, A. P. Windarto, and A. Wanto, "Penerapan Algoritma Clustering dalam Mengelompokkan Banyaknya Desa/Kelurahan Menurut Upaya Antisipasi/ Mitigasi Bencana Alam Menurut Provinsi dengan K-Means," KOMIK (Konferensi Nasional Teknologi Informasi dan Komputer), vol. 2, no. 1, pp. 311-319, 2018

[4] R. W. Sari, A. Wanto, and A. P. Windarto, "Implementasi Rapidminer dengan Metode K-Means (Study Kasus: Imunisasi Campak pada Balita Berdasarkan Provinsi)," KOMIK (Konferensi Nasional Teknologi Informasi dan Komputer), vol. 2, no. 1, pp. 224-230, 2018.

[5] S. Sudirman, A. P. Windarto, and A. Wanto, "Data Mining Tools | RapidMiner : K-Means Method on Clustering of Rice Crops by Province as Efforts to Stabilize Food Crops In Indonesia," IOP Conference Series: Materials Science and Engineering, vol. 420, no. 12089, pp. 1-8, 2018

[6] I. Parlina, A. P. Windarto, A. Wanto, and M. R. Lubis, "Memanfaatkan Algoritma K-Means dalam Menentukan Pegawai yang Layak Mengikuti Asessment Center untuk Clustering Program SDP," CESS (Journal of Computer Engineering System and Science), vol. 3, no. 1, pp. 87-93, 2018

[7] Sulastri, H. and Gufroni, A. I. (2017) 'Penerapan Data Mining Dalam Pengelompokan Penderita THALASSAEMIA', Jurnal Teknologi dan Sistem Informasi, 3(2), pp. 299-305.

[8] Srikanti, E. et al. (2018) 'Penerapan Algoritma Apriori Untuk Mencari Aturan Asosiasi Pada Data Peminjaman Buku Di Perpustakaan', Jurnal Ilmiah Rekayasa dan Manajemen Sistem Informasi, 4(1), pp. 77-80.

[9] Ummi, K. (2015) 'Analisa Data Mining Dalam Penjualan Sparepart Mobil Dengan Menggunakan Metode Algoritma Apriori', CRSID Journal, 8(3), pp. 155-164.

[10] Nursikuwagus, A. and Hartono, T. (2016) 'Implementasi Algoritma Apriori Untuk Analisis Penjualan Dengan Berbasis WEB', Junal SIMETRIS, 7(2), pp. 701-706.

[11] Haryati, S., Sudarsono, A. and Suryana, E. (2015) 'Implementasi Data Mining Untuk Memprediksi Masa Studi Mahasiswa Menggunakan Algoritma C4.5', Jurnal Media Informasi, 11(2), pp. 130-138. 